\title{
Hepatitis C Virus and Liver Transplantation
}

\author{
Kalyan Ram Bhamidimarri, MD, MPH, Sanjaya K. Satapathy, MBBS, MD, \\ and Paul Martin, MD
}

Dr Bhamidimarri is an assistant professor of clinical medicine and Dr Martin is a professor of medicine in the Division of Hepatology at the University of Miami Miller School of Medicine in Miami, Florida. Dr Satapathy is an associate professor of medicine in the Division of Surgery at the Methodist University Hospital Transplant Institute at the University of Tennessee Health Sciences Center in Memphis, Tennessee.

Address correspondence to: Dr Kalyan Ram Bhamidimarri University of Miami Miller School of Medicine

1120 NW 14th Street, Suite 1173

Miami, FL 33136

Tel: 305-243-3333

Fax: 305-243-3877

E-mail: kbhamidimarri@med.miami.edu

\section{Keywords}

Hepatitis C virus, direct-acting antiviral agents, liver transplantation, fibrosing cholestatic hepatitis

\begin{abstract}
Hepatitis C virus (HCV) is a major cause of death from infectious disease and is still the leading indication for liver transplantation in the United States and other Western countries. Alloral, direct-acting antiviral (DAA) therapies have revolutionized the field, with HCV cure rates of more than 90\% among treated patients. The safety and tolerability of these DAA agents have expanded the feasibility of HCV treatment even in the challenging pre- and post-liver transplant settings. However, the unique properties of DAA agents and the host profiles in these settings can limit the generalizability of HCV regimens, and prolongation of treatment duration or addition of ribavirin may be required in certain scenarios to optimize treatment outcomes. HCV therapy in the liver transplant setting is not one-size-fits-all; thus, this review summarizes the published data and emphasizes the applicability of currently available DAA therapies in patients with decompensated cirrhosis and in liver transplant recipients.
\end{abstract}

$\mathrm{H}$ epatitis $\mathrm{C}$ virus (HCV) remains the leading infectious cause of liver-related mortality in the developed world and accounts for approximately 700,000 deaths per year due to decompensated cirrhosis or hepatocellular carcinoma (HCC). ${ }^{1-3}$ The number of patients presenting with cirrhosis has doubled in the last 10 years and is projected to peak in the next decade. ${ }^{4,5}$ Although the number of decompensated cirrhotic patients has continued to increase, the organ donor pool has remained static over the last decade in the United States, resulting in increased liver transplant waitlist mortality. ${ }^{6}$ Direct-acting antiviral (DAA) therapies have changed the landscape of $\mathrm{HCV}$ due to their excellent safety profile and cure rates. ${ }^{7}$ Although several host-related variables determined the HCV treatment efficacy in the interferon era, decompensated cirrhosis is one of the few host factors that impacts cure rates in the DAA era. ${ }^{8}$ Earlier clinical trials excluded patients with decompensated cirrhosis; however, organ shortage and HCV recurrence have prompted the use of DAA agents in the setting of liver transplantation. This review 
summarizes the published literature to date regarding HCV therapies in the liver transplant setting (Table).

Cirrhosis is the final common pathway in the natural history of most chronic liver diseases leading to hepatic decompensation, HCC, or death in the absence of liver transplant. In the United States, HCV remains the most common etiology of cirrhosis and HCC and indication for liver transplantation. ${ }^{2}$ DAA therapy resulting in $\mathrm{HCV}$ cure can achieve improvement in hepatic function in cirrhotics, but the impact of such treatment in decompensated cirrhotics, especially in patients with Child-Turcotte-Pugh (CTP) class B or C, remains unclear. Untreated HCV prior to liver transplantation results in universal recurrence of the infection in the allograft, accelerated liver fibrosis, and subsequent graft failure. HCV is also associated with various extrahepatic risk factors and overall mortality, which add significantly to the economic and public health burden. ${ }^{9,10}$ Thus, there is compelling evidence to recommend treatment to all patients infected with HCV. With the availability of DAA agents in the United States, patients with advanced fibrosis as well as liver transplant recipients have been given priority for $\mathrm{HCV}$ treatment, as they experience the most benefit from $\mathrm{HCV}$ cure.

\section{Pre-Liver Transplant Setting}

The currently approved DAA agents have shown great efficacy and tolerability in HCV patients with advanced fibrosis and compensated cirrhosis. ${ }^{7}$ However, there are limited data regarding safety, efficacy, and costeffectiveness in decompensated cirrhotic patients with CTP class B or C. Among the currently approved DAA agents, simeprevir (Olysio, Janssen), paritaprevir/ritonavir/ombitasvir with or without dasabuvir (PRO/PROD; Viekira Pak, AbbVie and Technivie, AbbVie), and grazoprevir/elbasvir (Zepatier, Merck) are not recommended in patients with decompensated cirrhosis. In clinical trials, simeprevir has been known to cause modest elevation in bilirubin levels; however, there have been reports of markedly elevated bilirubin and hepatic decompensation in the postmarketing period even without the use of interferon. ${ }^{7}$ In a small case series, the combination of sofosbuvir (Sovaldi, Gilead) and simeprevir was well tolerated; sustained virologic response 12 weeks following the end of treatment (SVR12) was $74 \%$ and $100 \%$ in patients with HCV genotype 1a and $1 \mathrm{~b}$, respectively. ${ }^{11}$ A multicenter study using the same regimen in decompensated vs compensated cirrhotics reported lower SVR12 rates of $74 \%$ vs $91 \%$, respectively, and higher rates of adverse events (hospitalizations, infections, hepatic decompensation) and deaths in decompensated cirrhotics. ${ }^{12}$ The $\mathrm{PRO} / \mathrm{PROD}$ regimen is contraindicated in patients with decompensated cirrhosis due to reports of rapidly progressive hepatotoxicity with elevation in liver enzymes and bilirubin levels within the first month of treatment initiation. ${ }^{7}$ The US Food and Drug Administration has released a warning statement regarding the $\mathrm{PRO} / \mathrm{PROD}$ regimen, as there have been at least 2 deaths reported thus far. ${ }^{13}$ Even in compensated CTP class A cirrhotics, the $\mathrm{PRO} / \mathrm{PROD}$ regimen needs to be carefully monitored, and prompt discontinuation is recommended if there is a clinical suspicion for drug-induced liver injury. According to results of the C-SALT part A study, grazoprevir/ elbasvir in CTP class B decompensated cirrhotics yielded a SVR12 rate of $90 \%$, with 2 relapses and 1 patient death due to liver failure. ${ }^{14}$ Due to significant hepatic impairment, only half-dose grazoprevir $(50 \mathrm{mg})$ was used in this study rather than the commercially available dose of 100 $\mathrm{mg}$. There are currently no available data with the regimen in patients with CTP class $\mathrm{C}$ decompensated cirrhosis, and based upon data from the trial, the regimen is not endorsed in patients with decompensated cirrhosis. In summary, nonstructural (NS) 3/4 protease inhibitor-based regimens are currently not recommended to treat $\mathrm{HCV}$ in patients with decompensated cirrhosis. ${ }^{7}$

Sofosbuvir, either in combination with ledipasvir (Harvoni, Gilead), daclatasvir (Daklinza, Bristol-Myers Squibb), or velpatasvir (Epclusa, Gilead) with or without ribavirin, is approved for HCV treatment in the setting of decompensated CTP class B or C cirrhosis. Sofosbuvir/ ledipasvir plus ribavirin treatment in HCV genotypes 1 and 4 in both pre- and post-liver transplant settings for 12 or 24 weeks had shown promising results in the SOLAR-1 and SOLAR-2 trials. ${ }^{15,16}$ The overall SVR12 rate ranged from $85 \%$ to $89 \%$; however, the SVR 12 rates in patients with CTP class B and C ranged from $45 \%$ to $55 \%$ in the 2 studies, and the treatment duration did not significantly affect the efficacy. ${ }^{15,16}$ In another study, HCV genotypes 1 and 3 patients with decompensated cirrhosis were treated with sofosbuvir/ledipasvir or sofosbuvir plus daclatasvir with or without ribavirin for 12 weeks, with an overall SVR12 rate of approximately $80 \% \cdot{ }^{17}$ Similar results were also noted in the ALLY-1 study, in which patients who had multiple HCV genotypes $(1,2,3,4$, and 6) with decompensated cirrhosis or who were posttransplant were treated with sofosbuvir/daclatasvir for 12 weeks, and the SVR12 rate in genotype 1 was $82 \% .{ }^{18} \mathrm{~A}$ real-world European study treated 143 CTP class B and 22 CTP class C patients with sofosbuvir/daclatasvir with or without ribavirin for 24 weeks and reported SVR12 rates of $86 \%$ and $76 \%$, respectively. ${ }^{19}$ Sofosbuvir/velpatasvir with or without ribavirin for 12 weeks or without ribavirin for 24 weeks was used to treat HCV genotypes 1, 2, 3, 4 , and 6 in patients with decompensated cirrhosis in the ASTRAL-4 study, which reported an overall SVR12 rate 
Table. Cumulative Data From the Published Literature

\begin{tabular}{|c|c|c|c|c|c|c|c|c|c|}
\hline & Study & $\begin{array}{l}\text { CTP } \\
\text { Score }\end{array}$ & $\begin{array}{l}\text { Total } \\
\text { Patients }\end{array}$ & $\begin{array}{l}\text { DAA } \\
\text { Regimen }\end{array}$ & RBV & Duration & SVR12 & $\begin{array}{l}\text { FDA } \\
\text { Approved }\end{array}$ & $\begin{array}{l}\text { AASLD/IDSA } \\
\text { Recom- } \\
\text { mended }\end{array}$ \\
\hline \multirow[t]{6}{*}{ Pre-LT } & $\begin{array}{l}\text { Modi et } \mathrm{al}^{11} ; \\
\text { Saxena et } \mathrm{al}^{12}\end{array}$ & $\mathrm{~B} ; \mathrm{C}$ & $84 ; 13$ & $\begin{array}{l}\text { SIM + } \\
\text { SOF }\end{array}$ & $\pm \mathrm{RBV}$ & 12 weeks & $\begin{array}{l}-74 \% \\
-60 \%\end{array}$ & No & No \\
\hline & $\mathrm{FDA}^{13}$ & B; C & N/A & PROD & N/A & N/A & N/A & No & No \\
\hline & C-SALT part $\mathrm{A}^{14}$ & $\mathrm{~B}$ & 30 & GZP/EBR & No & 12 weeks & $90 \%$ & No & No \\
\hline & $\begin{array}{l}\text { ALLY- }{ }^{18} ; \text { Foster } \\
\text { et } \mathrm{al}^{17} \text {; Welzel et } \\
\mathrm{al}^{19}\end{array}$ & $\mathrm{~B} ; \mathrm{C}$ & $469 ; 78$ & $\begin{array}{l}\mathrm{DCV}+ \\
\mathrm{SOF}\end{array}$ & $\pm \mathrm{RBV}$ & $\begin{array}{l}12 \text { weeks; } \\
24 \text { weeks }\end{array}$ & $\begin{array}{l}-84 \% \\
-65 \%\end{array}$ & Yes & Yes \\
\hline & $\begin{array}{l}\text { SOLAR-1 }{ }^{16} \\
\text { SOLAR-2 }\end{array}$ & B; C & $115 ; 100$ & LED/SOF & $+\mathrm{RBV}$ & $\begin{array}{l}12 \text { or } 24 \\
\text { weeks }\end{array}$ & $\begin{array}{l}-90 \% \\
-84 \%\end{array}$ & Yes & Yes \\
\hline & ASTRAL- $4^{20}$ & B; C & $256 ; 11$ & VEL/SOF & $\pm \mathrm{RBV}$ & $\begin{array}{l}12 \text { or } 24 \\
\text { weeks }\end{array}$ & $-87 \%$ & Yes & Yes \\
\hline \multirow[t]{2}{*}{ Peri-LT } & Curry et $\mathrm{al}^{24}$ & $\mathrm{~B}$ & 28 & SOF & $+\mathrm{RBV}$ & Up to LT & $70 \%$ & No & No \\
\hline & Tawar et $\mathrm{al}^{25}$ & N/A & N/A & $\begin{array}{l}\text { Any DAA } \\
+ \text { HCIG }\end{array}$ & $\pm \mathrm{RBV}$ & $\begin{array}{l}12 \text { weeks } \\
\text { post-LT }\end{array}$ & $\mathrm{N} / \mathrm{A}$ & No & No \\
\hline \multirow[t]{6}{*}{ Post-LT } & Nguyen et $\mathrm{al}^{28}$ & N/A & 325 & $\begin{array}{l}\text { SIM + } \\
\text { SOF }\end{array}$ & $\pm \mathrm{RBV}$ & 12 weeks & $88 \%$ & No & Yes \\
\hline & CORAL- ${ }^{29}$ & N/A & 34 & PROD & $+\mathrm{RBV}$ & 24 weeks & $97 \%$ & Yes & Yes \\
\hline & ALLY-1 ${ }^{18}$ & N/A & 41 & $\begin{array}{l}\mathrm{DCV}+ \\
\mathrm{SOF}\end{array}$ & $+\mathrm{RBV}$ & 12 weeks & $95 \%$ & Yes & Yes \\
\hline & $\begin{array}{l}\text { SOLAR-1 }{ }^{16} \\
\text { SOLAR-2 }\end{array}$ & N/A & 212 & LED/SOF & $+\mathrm{RBV}$ & $\begin{array}{l}12 \text { or } 24 \\
\text { weeks }\end{array}$ & $-97 \%$ & Yes & Yes \\
\hline & N/A & N/A & N/A & GZP/EBR & N/A & N/A & N/A & No & No \\
\hline & N/A & N/A & N/A & VEL/SOF & N/A & N/A & $\mathrm{N} / \mathrm{A}$ & No & $\begin{array}{l}\text { No (but likely } \\
\left.\mathrm{ok}^{\mathrm{a}}\right)\end{array}$ \\
\hline \multirow[t]{4}{*}{ FCH } & $\begin{array}{l}\text { Forns et } \mathrm{al}^{36} \\
\text { Leroy et } \mathrm{al}^{38}\end{array}$ & N/A & 18 & SOF & $+\mathrm{RBV}$ & 24 weeks & $-80 \%$ & No & No \\
\hline & Issa et $\mathrm{al}^{37}$ & N/A & 5 & $\begin{array}{l}\text { SIM + } \\
\text { SOF }\end{array}$ & No & 24 weeks & $80 \%$ & $\mathrm{Ok}^{\mathrm{a}}$ & $\mathrm{Ok}^{\mathrm{a}}$ \\
\hline & Leroy et $\mathrm{al}^{38}$ & N/A & 10 & $\begin{array}{l}\mathrm{DCV}+ \\
\mathrm{SOF}\end{array}$ & No & 24 weeks & $96 \%$ & $\mathrm{Ok}^{\mathrm{a}}$ & $\mathrm{Ok}^{\mathrm{a}}$ \\
\hline & $\begin{array}{l}\text { SOLAR-1 }{ }^{16} \\
\text { SOLAR-2 }\end{array}$ & N/A & 11 & LED/SOF & $+\mathrm{RBV}$ & $\begin{array}{l}12 \text { or } 24 \\
\text { weeks }\end{array}$ & $100 \%$ & $\mathrm{Ok}^{\mathrm{a}}$ & $\mathrm{Ok}^{\mathrm{a}}$ \\
\hline
\end{tabular}

AASLD, American Association for the Study of Liver Diseases; CTP, Child-Turcotte-Pugh; DAA, direct-acting antiviral; DCV, daclatasvir; FCH, fibrosing cholestatic hepatitis; FDA, US Food and Drug Administration; GZP/EBR, grazoprevir/elbasvir; HCIG, hepatitis C immunoglobulin; IDSA, Infectious Diseases Society of America; LED/SOF, ledipasvir/sofosbuvir; LT, liver transplant; PROD, paritaprevir/ritonavir/ombitasvir with daclatasvir; RBV, ribavirin; SIM, simeprevir; SOF, sofosbuvir; SVR12, sustained virologic response 12 weeks following the end of treatment; VEL/SOF, velpatasvir/sofosbuvir.

${ }^{a}$ Use of this treatment is considered to be acceptable by the authors of this article but is not currently recommended by the FDA or AASLD/IDSA. 
of $87 \%{ }^{20}$ The group that received sofosbuvir/velpatasvir plus ribavirin for 12 weeks achieved the highest SVR12 rate $(94 \%)$ compared to the groups without ribavirin for 12 weeks $(83 \%)$ or 24 weeks ( $86 \%)$.

Common findings observed in all of the DAA therapy studies in decompensated cirrhotics are significantly lower SVR12 rates in patients with CTP class C compared to patients with CTP class B or A, and a substantial proportion who achieved SVR12 showing improvement in their liver function, CTP score (up to 50\%), or Model for End-Stage Liver Disease (MELD) score (up to 80\%). Inactivation or delisting from the liver transplant waitlist was feasible after successful HCV therapy and, therefore, $\mathrm{HCV}$ treatment is recommended in patients with a MELD score of less than 16 who are expected to derive the most benefit. In patients with a MELD score greater than 16 , only few cautiously selected patients may benefit from HCV treatment and, thus, the treatment can be deferred until after liver transplantation. ${ }^{21}$ Positive results reported in these studies could be a result of a cohort effect, as HCV treatment is only feasible due to the safe and well-tolerated DAA agents. In addition, treated patients may face a MELD purgatory effect and hampered access or delay in liver transplantation due to biochemical improvement (MELD score) but no meaningful clinical improvement. ${ }^{21} \mathrm{~A}$ minority of treated patients in the studies did experience serious adverse events and decline in liver function, which poses an important question of whether HCV therapy is cost-effective in all decompensated cirrhotics. A recent retrospective study reported higher rates of recurrent HCC in the immediate period following HCV eradication with DAA agents due to presumed immune alteration. ${ }^{22}$ However, the hypothesis was critiqued as speculative and erroneous, as data from 3 prospective cohorts did not demonstrate any increased risk of recurrent HCC in patients treated with DAA agents. ${ }^{23}$ Low-risk HCC patients with small tumors that have a higher likelihood of response to curative therapies may benefit from DAA therapy, whereas high-risk HCC patients with or without decompensated cirrhosis who need urgent liver transplantation would benefit from post-liver transplant HCV treatment. Future prospective studies would help address the several unanswered questions in this difficult-to-treat pre-liver transplant cohort. Among waitlisted patients, achieving SVR12 prior to liver transplantation prevents $\mathrm{HCV}$ recurrence in the allograft and is associated with favorable outcomes.

\section{Peri-Liver Transplant Setting}

Theoretically, a short course of DAA agents in the peritransplant period should be sufficient to prevent recurrent $\mathrm{HCV}$ in the allograft. The proof of concept was demonstrated in a study in which liver transplant candidates with HCC were treated with sofosbuvir and ribavirin for up to 48 weeks. ${ }^{24}$ Undetectability of HCV 28 days prior to liver transplantation proved to be an independent predictor of post-liver transplant SVR. ${ }^{24}$ DAA agents with shorter courses than the approved duration, combined with polyclonal HCV immunoglobulins, have also shown neutralization of several HCV variants and prevention of recurrent $\mathrm{HCV}$ infection in the allograft. ${ }^{25}$ $\mathrm{HCV}$ immunoglobulin is not yet approved, and its application in the real world needs to be determined. Fluid shifts, renal function, and variable pharmacokinetic patterns in the immediate postoperative period would also impact HCV therapy strategies.

\section{Post-Liver Transplant Setting}

Patients with HCV viremia at the time of liver transplantation universally develop recurrent $\mathrm{HCV}$ in the allograft, which results in accelerated fibrosis and negatively impacts graft and patient outcomes. Almost all DAA agents are approved for use in liver transplant recipients, and drug interactions need to be carefully monitored. The first all-oral therapy in liver transplant recipients was with sofosbuvir plus ribavirin for 24 weeks, which resulted in a SVR12 rate of $70 \% .{ }^{26}$ Simeprevir post-liver transplant has been studied only in phase 2 trials and is contraindicated in patients taking cyclosporine, as it can elevate drug levels 6-fold. ${ }^{7}$ However, sofosbuvir plus simeprevir has been evaluated in several HCV genotype 1 studies in the real-world setting and has demonstrated good efficacy and tolerability. Pooled SVR12 rates with the combination therapy were reported to be approximately $88 \%$, although liver transplant recipients with advanced fibrosis experienced lower efficacy. ${ }^{27,28}$ There is sufficient evidence that 24 weeks of sofosbuvir plus simeprevir is appropriate in patients with advanced fibrosis; however, given the paucity of data in the post-liver transplant setting, HCV guidelines recommend the combination regimen (with or without ribavirin) as an alternate option for 12 weeks in patients who take tacrolimus and have restrictions taking other regimens. ${ }^{7}$

Ritonavir in the PRO/PROD regimen has potentially significant drug-drug interactions and can elevate tacrolimus levels 57- to 86-fold and cyclosporine levels 4.3- to 5.8-fold. ${ }^{7}$ Therefore, close monitoring of immunosuppression and graft function is required during and after completion of PRO/PROD treatment. PROD plus ribavirin for 24 weeks in $34 \mathrm{HCV}$ genotype 1 liver transplant recipients demonstrated initial efficacy in the phase 2, open-label CORAL-I trial. ${ }^{29}$ SVR12 rates of $100 \%$ and $97 \%$ were reported in HCV genotypes $1 \mathrm{~b}$ and $1 \mathrm{a}$, respectively. It should be noted that the study participants 
had mild fibrosis (F0-F2), and the concerns for toxicity in patients with advanced fibrosis remain as in the pre-liver transplant setting. The longer duration (24 weeks) and adverse events of ribavirin also need to be considered when treating liver transplant recipients with this regimen. ${ }^{29}$

Sofosbuvir, daclatasvir, and ribavirin for 12 weeks were administered in liver transplant recipients with HCV genotypes 1, 3, and 6 in the open-label ALLY-I study. ${ }^{18}$ Liver transplant recipients had variable fibrosis scores as per FibroTest (APHP; marketed in the United States as FibroSure, LabCorp); 55\% had advanced fibrosis (F3 or F4). The reported SVR12 rates in HCV genotypes 1 and 3 were $95 \%$ and $91 \%$, respectively, and there were no treatment-specific safety signals. ${ }^{18} \mathrm{Few}$ other reports of daclatasvir plus simeprevir have demonstrated significantly lower SVR12 rates than daclatasvir plus sofosbuvir and, therefore, the former combination is not recommended, especially in patients with advanced liver disease. ${ }^{7}$ Daclatasvir does not cause clinically significant alterations of any of the immunosuppressive agents and has a good safety profile overall.

Sofosbuvir/ledipasvir in the post-liver transplant setting has more extensive data than any other DAA combination. SOLAR-1 was a phase 2, randomized, open-label study that enrolled 229 liver transplant recipients from the United States. ${ }^{16}$ Sofosbuvir/ledipasvir plus ribavirin was administered for 12 or 24 weeks. Liver transplant recipients without cirrhosis or compensated cirrhosis achieved SVR12 rates ranging from $96 \%$ to $98 \%$ regardless of the duration of the therapy. However, liver transplant recipients with CTP class B cirrhosis had a SVR12 rate of $85 \%$ with 12 weeks of treatment and $88 \%$ with 24 weeks of treatment. Patients with CTP class $\mathrm{C}$ cirrhosis had further reduction in SVR12 rates $(60 \%$ in the 12 -week arm vs $75 \%$ in the 24-week arm). SOLAR-2 had a study design similar to SOLAR-1, and was conducted in Europe, Canada, Australia, and New Zealand. ${ }^{15}$ The study enrolled 227 liver transplant recipients who received sofosbuvir/ledipasvir plus ribavirin for 12 or 24 weeks. SVR12 rates in patients without cirrhosis and compensated cirrhosis were $93 \%$ and $100 \%$ in the 12 -week arm and $100 \%$ and $96 \%$ in the 24-week arm, respectively. SVR12 rates with 12-week and 24-week therapy in CTP class B cirrhotics were $95 \%$ and $100 \%$, respectively; however, they were significantly lower in CTP class C cirrhotics $50 \%$ and $80 \%$, respectively). There were 3 deaths unrelated to HCV therapy in SOLAR-1 and 1 death in SOLAR-2 in the post-liver transplant cohort, most commonly due to sepsis. ${ }^{15,16}$ The importance of adding ribavirin to sofosbuvir/ledipasvir is purely empiric, as all patients in the SOLAR-1 and -2 studies received ribavirin. Several real-world case series have been published regarding the use of the regimen with or without ribavirin; however, the role of ribavirin could not be ascertained. ${ }^{30-32}$ Interestingly, in the most recent multicenter series, sofosbuvir/ledipasvir was also used in an 8-week arm in this post-liver transplant cohort without ribavirin as per the criteria in the package insert of the regimen, and a SVR12 rate of $86 \%$ was reported. ${ }^{31}$ SVR12 rates with 12 or 24 weeks of treatment without ribavirin were $94 \%$ and $95 \%$, respectively, and $97 \%$ and $100 \%$ with ribavirin, respectively. In the absence of strong evidence, the addition of ribavirin in the post-liver transplant setting appears to enhance the SVR12 rate, at least in patients with advanced liver disease.

Grazoprevir/elbasvir has not been studied in the post-liver transplant setting and, thus, the regimen is not recommended. ${ }^{7}$ The combination therapy has significant drug-drug interactions causing elevation of tacrolimus levels by $43 \%$ or notable elevation of grazoprevir levels by $15 \%$ when used in combination with cyclosporine. Velpatasvir has a similar profile to ledipasvir, and no significant drug interactions are expected when used in combination with tacrolimus or cyclosporine. The sofosbuvir/velpatasvir combination is commercially available, but given the lack of data in the post-liver transplant setting, its use, although feasible, is not yet recommended for this cohort. ${ }^{7}$

\section{Fibrosing Cholestatic Hepatitis}

Fibrosing cholestatic hepatitis (FCH) is a severe form of HCV recurrence that occurs in approximately $10 \%$ of liver transplant recipients and results in progressive hepatic dysfunction and graft failure within months following liver transplantation. ${ }^{33,34} \mathrm{FCH}$ has also been reported due to hepatitis $\mathrm{B}$ virus and cytomegalovirus. Among liver transplant recipients, $\mathrm{HCV}$-related FCH is typically encountered in $\mathrm{HCV}$ genotype $1, \mathrm{HIV} / \mathrm{HCV}$ coinfection, intense immunosuppression, and older donors/recipients, and it is characterized by the presence of a very high viral load and divergent quasispecies. ${ }^{35} \mathrm{In}$ the interferon era, the condition was associated with poor treatment response and was generally fatal, with high graft and patient loss. Sofosbuvir plus ribavirin for 24 or 48 weeks in the compassionate use program laid the proof of concept regarding the efficacy of DAA agents for this patient population. ${ }^{36}$ Ten patients who met the definition of FCH were treated, and 80\% achieved SVR12. Two patients underwent liver retransplantation, and the rest improved or remained stable without the need for retransplantation. The addition of simeprevir to sofosbuvir in 5 FCH patients resulted in an $80 \%$ SVR12 rate with 24-week therapy. ${ }^{37}$ In a study of $23 \mathrm{FCH}$ patients, 15 patients received sofosbuvir plus daclatasvir and 8 patients 
received sofosbuvir plus ribavirin..$^{38}$ Rapid and dramatic clinical improvement was noted with 24 weeks of therapy without the need for liver retransplantation. Interestingly, although the rapid virologic response rates were low, 96\% of the treated patients achieved SVR12. A total of $11 \mathrm{FCH}$ patients were treated with sofosbuvir/ledipasvir plus ribavirin in the SOLAR-1 and -2 trials, and regardless of the duration of the therapy, all patients achieved SVR12. ${ }^{15,16}$ Dramatic biochemical improvement was noted after HCV treatment, and no deaths were reported in this cohort. A recent real-world, multicenter study also reported a SVR12 rate of $100 \%$ in $6 \mathrm{FCH}$ patients. ${ }^{31}$ Data from all these studies show strong evidence that DAA agents are not only efficacious in treating $\mathrm{FCH}$ but also prevent graft loss, retransplantation, and death.

\section{Summary}

HCV treatment is the most cost-effective before a patient becomes cirrhotic. Interferon-based therapies were considered risky in compensated cirrhotics and were contraindicated in decompensated cirrhotics. DAA agents have revolutionized the HCV therapeutic field in recent years, and challenging populations such as decompensated cirrhotics and liver transplant recipients are now able to undergo successful treatments with minimal risk. A European study of liver transplant candidates who underwent DAA therapy reported 33\% inactivation and $19 \%$ delisting rates from the transplant waiting list at 60 weeks. ${ }^{21}$ Patients with a baseline MELD score lower than 16 had higher SVR12 rates and reliably higher chances of becoming delisted than those with higher MELD scores. The authors have further suggested that the decision to treat with DAA agents needs to be individualized in patients with MELD scores between 16 and 20 and that treatment should possibly be deferred until after liver transplantation in patients with MELD scores greater than $20 .{ }^{21}$ It is becoming evident that $\mathrm{HCV}$ treatment is associated with favorable outcomes even in the decompensated cirrhosis setting, but further research is needed regarding whether the treatment could reverse the natural history and avoid the need for liver transplantation. DAA therapy might rapidly improve biochemical indices and MELD scores, but manifestations, including ascites, encephalopathy, and portal hypertensive complications, take a longer time to resolve. With the evolution of several DAA molecules, choosing the right regimen and the optimal timing of HCV treatment are essential to ensure the best patient outcomes.

DAA therapy is considerably safe and efficacious in patients with compensated cirrhosis (CTP class A). Among the decompensated cirrhotics, it is now evident that CTP class B cirrhotics have better treatment response and fewer adverse events with DAA therapy compared to CTP class $C$ cirrhotics. NS3/4 protease inhibitor-based regimens are metabolized in the liver and, therefore, are not recommended in this setting. Sofosbuvir in combination with any NS5A analog, daclatasvir, ledipasvir, or velpatasvir has reportedly good safety and efficacy data. The addition of ribavirin (low ascending dose protocol) allows the treatment duration to be truncated to 12 weeks without a major attrition in SVR12 rates. In the peritransplant setting, listed patients who are aviremic for at least 1 month prior to their liver transplant (while being treated) could remain aviremic without $\mathrm{HCV}$ recurrence post-liver transplantation. $\mathrm{HCV}$ immunoglobulin is being investigated as an adjunct to DAA therapy in this setting. HCV treatment in the decompensated cirrhosis setting has several advantages: (1) HCV cure prior to liver transplantation could prevent allograft infection with HCV, and (2) improvement or stabilization of hepatic function could result in potential delisting and avoiding the need for liver transplantation. However, treating $\mathrm{HCV}$ in this setting is disadvantageous in certain scenarios: (1) it may not be cost-effective due to lower response rates, longer treatment durations, the need to use ribavirin, and the management of adverse events; (2) improvement in the MELD score with HCV treatment can potentially increase the wait time for transplant and could contribute to waitlist mortality; and (3) patients could not avail themselves of shorter wait time by receiving HCV-positive organs, especially in high MELD score regions. HCV therapy may not be feasible in some scenarios such as hepatorenal syndrome or if the glomerular filtration rate declines to less than $30 \mathrm{~mL} / \mathrm{min}$. In the post-liver transplant setting, treating the patient before the development of advanced fibrosis in the graft has the best outcomes. Drug-drug interactions and immunosuppression need to be closely monitored in this patient population. Several cost-effective models proposed recently suggest that HCV treatment in the pre-liver transplant setting is a better strategy overall, although a personalized approach to each decompensated cirrhotic patient cannot be undermined. ${ }^{40}$ Pangenotypic DAA agents are expected to get approved in the near future, and competitive pricing is also expected, which would continue to transform the $\mathrm{HCV}$ treatment strategies. Current data analysis from the National Health and Nutrition Exam Survey, HealthCore, and United Network for Organ Sharing demonstrates that $\mathrm{HCV}$ as an indication for liver transplant is decreasing, while nonalcoholic steatohepatitis and alcoholic liver disease are rising in proportion. ${ }^{39}$ As more $\mathrm{HCV}$ patients achieve cure with these DAA regimens, the liver transplant trend for HCV in the future would be expected to mimic the observed trend for hepatitis B virus in the past decade. 
Dr Bhamidimarri has served on the scientific advisory board for Gilead, AbbVie, and Bristol-Myers Squibb. Dr Martin has been a consultant and investigator for Gilead, AbbVie, Merck, and Janssen. Dr Satapathy has served as a consultant for Gilead, Intercept, and AbbVie, and receives research grant support from Shire/NASH, Genfit, Conatus Pharmaceuticals, and Biotest Pharmaceuticals.

\section{References}

1. Kanwal F, Hoang T, Kramer JR, et al. Increasing prevalence of HCC and cirrhosis in patients with chronic hepatitis C virus infection. Gastroenterology. 2011;140(4):1182-1188.e1.

2. Beste LA, Leipertz SL, Green PK, Dominitz JA, Ross D, Ioannou GN. Trends in burden of cirrhosis and hepatocellular carcinoma by underlying liver disease in US veterans, 2001-2013. Gastroenterology. 2015;149(6):1471-1482.e5; quiz e17-e18. 3. Benvegnù L, Gios M, Boccato S, Alberti A. Natural history of compensated viral cirrhosis: a prospective study on the incidence and hierarchy of major complications. Gut. 2004;53(5):744-749.

4. Razavi H, Waked I, Sarrazin C, et al. The present and future disease burden of hepatitis $\mathrm{C}$ virus (HCV) infection with today's treatment paradigm. J Viral Hepat. 2014;21(suppl 1):34-59.

5. Davis GL, Alter MJ, El-Serag H, Poynard T, Jennings LW. Aging of hepatitis $\mathrm{C}$ virus $(\mathrm{HCV})$-infected persons in the United States: a multiple cohort model of HCV prevalence and disease progression. Gastroenterology. 2010;138(2):513-521, 521.e1-e6.

6. Fayek SA, Quintini C, Chavin KD, Marsh CL. The current state of liver transplantation in the United States: perspective from American Society of Transplant Surgeons (ASTS) Scientific Studies Committee and endorsed by ASTS Council. Am J Transplant. 2016;16(11):3093-3104.

7. Chung RT, Davis GL, Jensen D, et al; AASLD/IDSA HCV Guidance Panel. Hepatitis $\mathrm{C}$ guidance: AASLD-IDSA recommendations for testing, managing, and treating adults infected with hepatitis C virus. Hepatology. 2015;62(3):932-954. 8. Craxì A, Perno CF, Viganò M, Ceccherini-Silberstein F, Petta S; AdHoc (Advancing Hepatitis $\mathrm{C}$ for the Optimization of Cure) Working Party. From current status to optimization of $\mathrm{HCV}$ treatment: recommendations from an expert panel. Dig Liver Dis. 2016;48(9):995-1005.

9. van der Meer AJ, Veldt BJ, Feld JJ, et al. Association between sustained virological response and all-cause mortality among patients with chronic hepatitis $\mathrm{C}$ and advanced hepatic fibrosis. JAMA. 2012;308(24):2584-2593.

10. Backus LI, Boothroyd DB, Phillips BR, Belperio P, Halloran J, Mole LA. A sustained virologic response reduces risk of all-cause mortality in patients with hepatitis C. Clin Gastroenterol Hepatol. 2011;9(6):509-516.e1.

11. Modi AA, Nazario H, Trotter JF, et al. Safety and efficacy of simeprevir plus sofosbuvir with or without ribavirin in patients with decompensated genotype 1 hepatitis C cirrhosis. Liver Transpl. 2016;22(3):281-286.

12. Saxena V, Nyberg L, Pauly M, et al. Safety and efficacy of simeprevir/sofosbuvir in hepatitis C-infected patients with compensated and decompensated cirrhosis. Hepatology. 2015;62(3):715-725.

13. US Food and Drug Administration. FDA drug safety communication: FDA warns of serious liver injury risk with hepatitis $\mathrm{C}$ treatments Viekira Pak and Technivie. https://www.fda.gov/Drugs/DrugSafety/ucm468634.htm. Published October 22, 2015. Updated August 24, 2016. Accessed March 20, 2017.

14. Jacobson IM, Poordad F, Firpi-Morell R, et al. O008: Efficacy and safety of grazoprevir and elbasvir in hepatitis $\mathrm{C}$ genotype 1-infected patients with ChildPugh class B cirrhosis (C-SALT part A). J Hepatol. 2015;62(suppl 2):S193-S194. 15. Manns M, Samuel D, Gane EJ, et al; SOLAR-2 investigators. Ledipasvir and sofosbuvir plus ribavirin in patients with genotype 1 or 4 hepatitis $C$ virus infection and advanced liver disease: a multicentre, open-label, randomised, phase 2 trial. Lancet Infect Dis. 2016;16(6):685-697.

16. Charlton M, Everson GT, Flamm SL, et al; SOLAR-1 Investigators. Ledipasvir and sofosbuvir plus ribavirin for treatment of HCV infection in patients with advanced liver disease. Gastroenterology. 2015;149(3):649-659.

17. Foster GR, Irving WL, Cheung MC, et al; HCV Research, UK. Impact of direct acting antiviral therapy in patients with chronic hepatitis $\mathrm{C}$ and decompensated cirrhosis. J Hepatol. 2016;64(6):1224-1231.

18. Poordad F, Schiff ER, Vierling JM, et al. Daclatasvir with sofosbuvir and ribavirin for hepatitis $\mathrm{C}$ virus infection with advanced cirrhosis or post-liver transplantation recurrence. Hepatology. 2016;63(5):1493-1505.
19. Welzel TM, Petersen J, Herzer K, et al. Daclatasvir plus sofosbuvir, with or without ribavirin, achieved high sustained virological response rates in patients with HCV infection and advanced liver disease in a real-world cohort. Gut. 2016;65(11):1861-1870

20. Curry MP, O'Leary JG, Bzowej N, et al; ASTRAL-4 Investigators. Sofosbuvir and velpatasvir for $\mathrm{HCV}$ in patients with decompensated cirrhosis. $N$ Engl J Med. 2015;373(27):2618-2628.

21. Belli LS, Berenguer M, Cortesi PA, et al; European Liver and Intestine Association (ELITA). Delisting of liver transplant candidates with chronic hepatitis $\mathrm{C}$ after viral eradication: a European study. J Hepatol. 2016;65(3):524-531.

22. Reig M, Marińo Z, Perelló C, et al. Unexpected high rate of early tumor recurrence in patients with $\mathrm{HCV}$-related $\mathrm{HCC}$ undergoing interferon-free therapy. $J$ Hepatol. 2016;65(4):719-726

23. ANRS collaborative study group on hepatocellular carcinoma (ANRS CO22 HEPATHER, CO12 CirVir and CO23 CUPILT cohorts). Lack of evidence of an effect of direct-acting antivirals on the recurrence of hepatocellular carcinoma: data from three ANRS cohorts. J Hepatol. 2016;65(4):734-740.

24. Curry MP, Forns X, Chung RT, et al. Sofosbuvir and ribavirin prevent recurrence of HCV infection after liver transplantation: an open-label study. Gastroenterology. 2015;148(1):100-107.e1.

25. Tawar RG, Heydmann L, Bach C, et al. Broad neutralization of hepatitis $\mathrm{C}$ virus-resistant variants by Civacir hepatitis $\mathrm{C}$ immunoglobulin. Hepatology. 2016;64(5):1495-1506

26. Charlton M, Gane E, Manns MP, et al. Sofosbuvir and ribavirin for treatment of compensated recurrent hepatitis $\mathrm{C}$ virus infection after liver transplantation. Gastroenterology. 2015;148(1):108-117.

27. Gutierrez JA, Carrion AF, Avalos D, et al. Sofosbuvir and simeprevir for treatment of hepatitis $\mathrm{C}$ virus infection in liver transplant recipients. Liver Transpl. 2015;21(6):823-830

28. Nguyen NH, Yee BE, Chang C, et al. Tolerability and effectiveness of sofosbuvir and simeprevir in the post-transplant setting: systematic review and metaanalysis. BMJ Open Gastroenterol. 2016;3(1):e000066.

29. Kwo PY, Mantry PS, Coakley E, et al. An interferon-free antiviral regimen for HCV after liver transplantation. $N$ Engl J Med. 2014;371(25):2375-2382.

30. Ciesek S, Proske V, Otto B, et al. Efficacy and safety of sofosbuvir/ledipasvir for the treatment of patients with hepatitis $\mathrm{C}$ virus re-infection after liver transplantation. Transpl Infect Dis. 2016;18(3):326-332.

31. Kwok RM, Ahn J, Schiano TD, et al. Sofosbuvir plus ledispasvir for recurrent hepatitis C in liver transplant recipients. Liver Transpl. 2016;22(11):1536-1543.

32. Faisal N, Bilodeau M, Aljudaibi B, et al. Sofosbuvir-based antiviral therapy is highly effective in recurrent hepatitis $\mathrm{C}$ in liver transplant recipients: Canadian multicenter "real-life" experience. Transplantation. 2016;100(5):1059-1065.

33. Terrault N. Liver transplantation in the setting of chronic HCV. Best Pract Res Clin Gastroenterol. 2012;26(4):531-548.

34. Verna EC, Abdelmessih R, Salomao MA, Lefkowitch J, Moreira RK, Brown RS Jr. Cholestatic hepatitis C following liver transplantation: an outcomebased histological definition, clinical predictors, and prognosis. Liver Transpl. 2013;19(1):78-88

35. Satapathy SK, Sclair S, Fiel MI, Del Rio Martin J, Schiano T. Clinical characterization of patients developing histologically-proven fibrosing cholestatic hepatitis C post-liver transplantation. Hepatol Res. 2011;41(4):328-339.

36. Forns X, Charlton M, Denning J, et al. Sofosbuvir compassionate use program for patients with severe recurrent hepatitis $\mathrm{C}$ after liver transplantation. Hepatology. 2015;61(5):1485-1494

37. Issa D, Eghtesad B, Zein NN, et al. Sofosbuvir and simeprevir for the treatment of recurrent hepatitis $\mathrm{C}$ with fibrosing cholestatic hepatitis after liver transplantation. Int J Organ Transplant Med. 2016;7(1):38-45.

38. Leroy V, Dumortier J, Coilly A, et al; Agence Nationale de Recherches sur le SIDA et les Hépatites Virales CO23 Compassionate Use of Protease Inhibitors in Viral C in Liver Transplantation Study Group. Efficacy of sofosbuvir and daclatasvir in patients with fibrosing cholestatic hepatitis $\mathrm{C}$ after liver transplantation. Clin Gastroenterol Hepatol. 2015;13(11):1993-2001.e1-2.

39. Goldberg D, Ditah IC, Saeian K, et al. Changes in the prevalence of hepatitis $\mathrm{C}$ virus infection, nonalcoholic steatohepatitis, and alcoholic liver disease among patients with cirrhosis or liver failure on the waitlist for liver transplantation [published online January 11, 2017]. Gastroenterology. doi:10.1053/j. gastro.2017.01.003.

40. Ahmed A, Gonzalez SA, Cholankeril G, et al. Treatment of patients waitlisted for liver transplant with an all-oral DAAs is a cost-effective treatment strategy in the United States [published online March 3, 2017]. Hepatology. doi:10.1002/ hep. 29137. 